\title{
Tactical Decision Games: Developing Scenario-Based Training for Decision-Making in Distributed Teams
}

\author{
Kristina Lauche \\ Delft University of Technology \\ k.lauche@tudelft.nl \\ Petra Saskia Bayerl \\ Delft University of Technology \\ p.s.bayerl@tudelft.nl
}

\author{
Margaret Crichton \\ People Factor Consultants Ltd. \\ margaret@peoplefactor.co.uk
}

\begin{abstract}
Motivation - Team training should reflect the increasing complexity of decision-making environments. Research approach - Guidelines for scenario-based training were adopted for a distributed setting and tested in a pilot training session with a distributed team in the offshore oil industry. Findings - Participants valued the scenario as challenging and useful, but also highlighted problems of distributed communication. The findings were used to improve the training as well as current use of the technology in the organisation. Research limitations/Implications - Although the findings are currently only based on one pilot, they provide insights for adopting scenario-based training for computer-rich, distributed settings. Originality/Value - The research extends current scenario-based training towards distributed work arrangements in high-technology settings and provides practical advice to developers and implementers. Take away message - If everyday work is computermediated, psychological fidelity cannot mean collocated/low-tech training; however it is worthwhile paying close attention to which aspects of technology are integrated into a training environment.
\end{abstract}

Keywords

Tactical decision games, scenario-based training, scenario development, distributed teams, offshore oil industry

\section{INTRODUCTION}

This paper discusses how training methods that have previously been successfully used in the context of Naturalistic Decision Making can be adapted to distributed settings. In many domains such as aviation, emergency response or military operations distributed working and the use of computer-mediated team communication and online monitoring of data is already a reality. Distribution is often inherent in the nature of the task, and efficient coordination across dispersed subgroups is vital in these dynamic and potentially hazardous situations to guarantee speed and accuracy of responses. Our research was conducted in the offshore oil and gas industry, which is similar to the above domains in its dynamic and potentially hazardous nature. It is also characterised by an inherent distribution between where hydrocarbons are found and suitable office locations, typically labelled 'offshore' and 'onshore', with distinct subgroups and division of labour between locations. It is also driven by industrial concerns: comparable to commercial aviation, mistakes and delays can have serious financial consequences. Therefore, reducing time to recovery and minimizing risks is of highest importance for safety as well as financial reasons. The industry has a lot of experience in distributed working but has recently embarked on making more use of increased technological capabilities for onshoreoffshore communication.

Undoubtedly, distributed teams now have more sophisticated and powerful technology at their hands, using continuously richer media and offering more options for real-time data exchange and joint data manipulation. Yet, the fact remains that decision-making over distances and different locations poses specific challenges that may not be easily remedied by providing better technology. As a meta-analysis by Baltes et al. (2002) suggests, distributed teams consistently show lower effectiveness in decision-making tasks, more time needed to complete tasks, and decreased member satisfaction when compared to teams in face-to-face conditions. In contrast, team members working face-toface seem better informed, make more recommendations predictive of correct decisions, and tend to show higher confidence in decisions than their distributed counterparts (e.g., Crede \& Sziezik, 2003; Hedlung, Ilgen, \& Hollenbeck, 1998). Also, the provision of better technologies does not automatically mean that teams adopt or integrate these effectively into their work processes (e.g., Lauche, 2007).

Extensive research into teams and team performance has consistently shown that teams not only need technical skills but also task- and team-work related knowledge, skills and attitudes to succeed (Salas \& Cannon-Bowers, 1997). The 
recent trend towards distributed working introduces additional challenges for which team members need to be prepared. To overcome these specific challenges connected with remote working, supplemental skills such as self-management skills, interpersonal trust, and intercultural skills are required (e.g., Hertel, Konradt, \& Voss, 2006). Team training is a promising way to improve non-technical skills and increase the preparedness and communication efficiency in distributed teams (e.g., Warkentin \& Beranek, 1999). Often, however, organizations either ignore the need for specific training (Rosen, Furst, \& Blackburn, 2006) or restrict training to the technological aspect. The additional challenges of distributed teams, such as group coordination and cross-cultural awareness (Blackburn, Furst \& Rosen, 2003) are seldom addressed.

A critical issue in developing training is the transfer from the training environment to the workplace. In their seminal review on training transfer, Baldwin and Ford (1988) highlighted the gap between what is addressed during training and what participants can and will implement in their normal work environment afterwards. A recent review of the training transfer literature in various disciplines (Burke \& Hutchins, 2007) found strong support for learner characteristics such as self-efficacy, pre-training motivation and perceived utility, as well as aspects of training design such as content relevance, practice and feedback and behavioural modelling. In order to increase the likelihood of transfer into posttraining behaviours and organisational benefits, training initiatives should build up mastery experience (Bandura, 1997) in a plausible setting that is perceived as interesting and challenging. Scenario-based training, or tactical decision games (TDGs), in the area of Naturalistic Decision Making are based on these principles. TDGs have been used to practise decision making under complex, dynamic and stressful conditions to prepare for the unexpected in areas such as military (Klein, 1999) or emergency response (Crichton, Flin \& Rattray, 2000; Ringland, 1998). TDGs have typically been aimed at psychological fidelity rather than technical resemblance to the actual work environment, based on the argument that it is more important that team members experience challenge and stress than that they are impressed by the technology of the simulation (Kozlowski \& DeShon, 2004).

Considering the pivotal role of correct decisions in fields such as space flight, the military, or the offshore oil industry, the knowledge of how to react and interact in critical situations can help prevent costly errors, save time and potentially lives. It thus seems crucial to systematically prepare teams in such areas for the challenges involved in coordinating across remote subgroups during critical situations, instead of relying on 'training on the job'. If competent use of computer-based tools and distributed working become an essential part of the job, the training environment should incorporate at least parts of these aspects into the scenario if it is not to lose its psychological validity. The training environment thus should include both technical and non-technical issues in parallel.

This paper discusses requirements for such training interventions and describes the development of a scenario for decision-making training in distributed teams and preliminary results from its implementation in the field. Based on these results initial recommendations for the development of scenarios for decision-making training in distributed teams are developed.

\section{DEVELOPING SCENARIO-BASED TRAINING}

Tactical decision games are one of a number of techniques employed for decision-making training, especially in critical incidents, such as exercises, simulations, case studies of major incidents, lectures, directed reading, and on the job learning (Flin, 1996). TDGs have traditionally been utilised to train non-technical skills in individuals (Crichton, Flin \& Rattray, 2000; Klein, 1998; Schmitt, 1998), and more recently extended to prepare teams for operations (Crichton, 2009; Woltjer et al, 2006). Repeated exposure to scenario-based training, using a variety of scenarios, allows novice decision makers to enhance their experience, build up principles for response, and accelerate their decision-making abilities (Cannon-Bowers \& Bell, 1997). Decision skills training programmes have been developed around scenariobased training to develop decision-making strategies by, for example, engaging in deliberate practice, obtaining feedback that is accurate and diagnostic, building mental models, developing meta-cognitive skills and encouraging self-reflection to improve learning (Oser, 1999; Pliske, McCloskey \& Klein, 2001).

In contrast to desktop and full-scale exercises where the focus is typically on knowing and implementing existing procedures, TDGs are specifically designed to present the players with a dilemma where there is no 'right' answer. Players must instead draw on their experience to assess the situation and find a possible solution to the problem. One of the critical features of a TDG is to develop a challenging, complex scenario that culminates in the dilemma, or critical situation (Badke-Schaub, 1999). The following six stages are typically involved in designing a TDG scenario (Flin \& Crichton, 2000; van den Bosch \& Riemersma, 2004).

1. Definition of purpose: Determine the main focus of the exercise and key roles to be involved.

2. Choice of dilemma: Identify a critical situation including the location, phase and severity of the incident and resources available. Check that there are several possible solutions and that non-technical skills can be practiced in this setting.

3. Input from Subject Matter Experts (SMEs): Gather information on situational factors, relevant technical data, potential evolutions of the incident and contingencies. 
4. Development of scenario background: Construct a scenario (with assistance from SMEs as required) with details of how the incident occurred, technical data, and actions previously taken. Include ambiguous or misleading information and omit some relevant information to increase the challenge of the scenario.

5. Preparation of script including materials and visualisation: Present the scenario as a story including what participants are required to do, such as preparing a briefing (situational assessment) for other people or describing the decision made and actions to be taken. Provide additional material such as a diagram of the location of the incident, technical parameters, etc.

6. Identify performance criteria: Describe behavioural markers of appropriate actions based on a cognitive task analysis for the purpose of feedback and evaluation. The criteria should be formulated as skills, not as a predetermined 'right' answer.

As complex problems often extend the duration of a typical training situation, scenarios provide an excellent format for 'expanding' and 'shrinking' time. Players can practice decision making in difficult situations in slow motion, or they can be fast-forwarded to the next day or a shift-handover. These jumps in time should be conveyed with sufficient detail so that participants can elaborate and act on the situation.

If the scenario is to be used for a team, it should address information sharing and the need for coordination in a way that ideally all team members are required to contribute to the decision-making process. The scenario should therefore present diverse information that allows for multiple interpretations and solutions, thereby stimulating discussions about its relevance and implications, which in turn should increase shared situation awareness. In line with the criteria identified in the training transfer literature, the scenario should be motivating in the sense that it is perceived as interesting and challenging. It should be pitched at the appropriate level in terms of participants' skill level and selfefficacy to build up mastery experience.

A specific challenge in devising TDGs for distributed teams is to identify which aspects of the distributed and computer-mediated environment should be replicated in the training, and how. The technology choices need to be plausible and relevant: if participants would normally be monitoring a stream of data, samples of these data should be included; if a specific communication technology is used for interaction between remote subgroups, this should be emulated, possibly including a breakdown scenario in which this particular technology fails. The training should also address challenges of team composition, such as functional heterogeneity, which is often higher than in collocated teams (Griffith, Sawyer, \& Neale, 2003), or asymmetry between subgroups in terms of cultures, demographic/educational attributes, etc. Distributed teams are less likely to have established common practices and may need to resolve more substantial differences in perspectives during the scenario.

Based on the above considerations, we argue that TDGs for distributed teams should: 1) incorporate functional and status diversity, 2) retain geographical distribution, and 3) aim for (a degree of) technological realism. With the inclusion of multiple functions and technological capabilities scenario-based workshops move away from a pure scenario methodology closer towards game simulations (cf. Alexander, 2000).

\section{EXEMPLAR SCENARIO DEVELOPMENT FOR DRILLING TEAMS}

In the context of a larger project on the introduction of Collaborative Environments in a major oil and gas company (see Bayerl \& Lauche, 2008; Lauche, 2008), we developed and implemented a distributed scenario-based decision-making workshop for drilling teams. Decision-making in drilling teams involves multiple functions and hierarchical levels as well as different groups of geographically distributed personnel such as office, rig and vendors (see Figure 1). The introduction of Collaborative Environments has increased the use of computer-mediated communication and data sharing between remote subgroups (e.g., video-links, desktop sharing) as well as the use of real-time data and modelling software. 


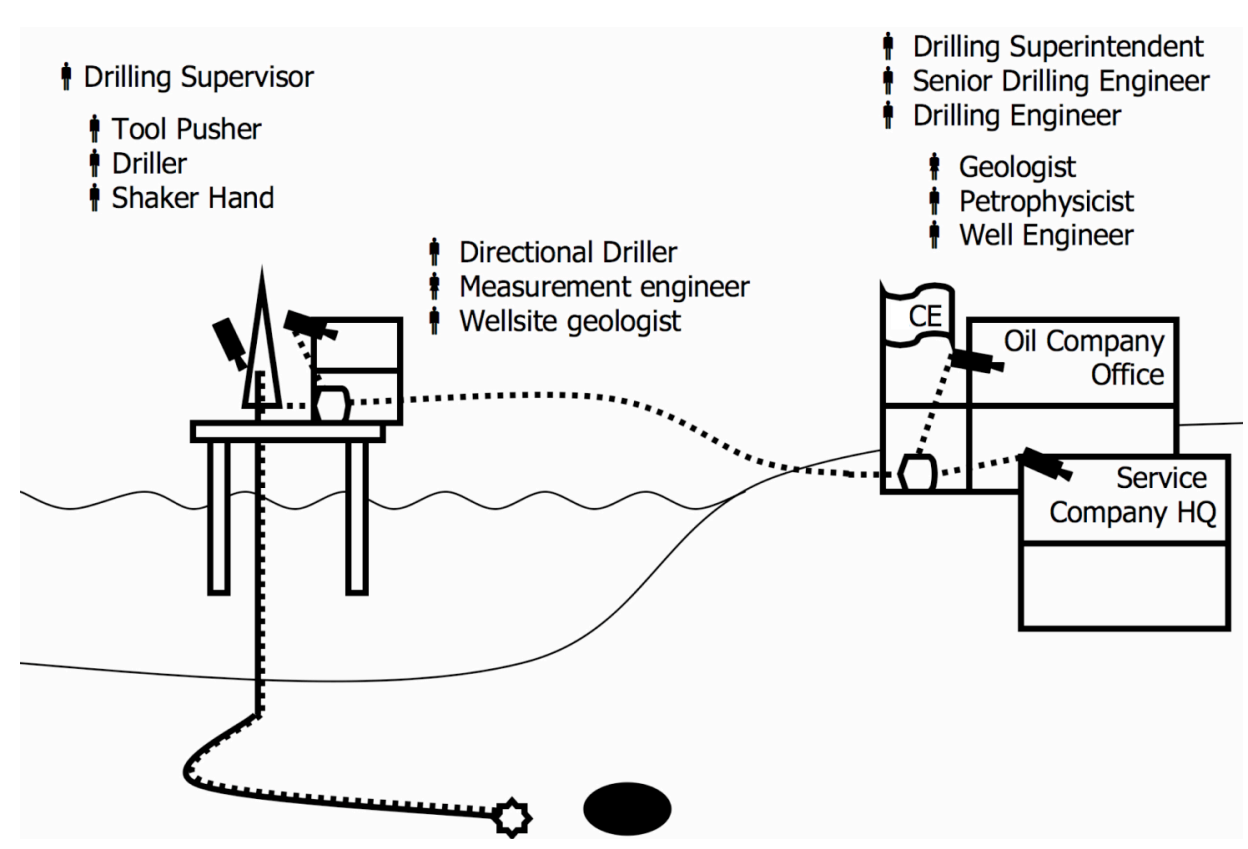

Figure 1. Typical Layout of Distributed Drilling Teams with Information Flow

\section{Scenario Development}

A workshop was conceptualized as a pilot to test the scenario and gather practical experience with this type of training. The scenario was designed following the stages outlined above.

1. Definition of purpose: Preliminary interviews with middle management were used to identify the main training objectives as well as key roles to be involved from onshore and offshore.

2. Choice of critical situation: A list of critical situations with more than one possible solution was collected from SMEs in the drilling community based on personal experiences of critical situations in the past. Of these, one particularly challenging situation was selected. Supplementary details were gathered from SMEs' experiences of operations and critical decisions, recollections of challenging situations experienced by other teams, and interviews conducted with personnel in the domain to identify key judgments and decisions, as well as critical factors influencing decision-making in these situations. The final scenario was thus an abstraction from a number of episodes rather than an identifiable specific incident.

3. SME input: A senior drilling expert and a geologist involved in the selected critical situation provided information for a scenario draft, which was then reviewed and expanded by additional SMEs in terms of situational factors, especially technical data, the possible evolution of the incident and potential contingencies. The resident technology coach determined which archival data sets to use, how to modify and present this information, and how to integrate technological capabilities into the flow of the training.

4 and 5. Scenario background, script, and diagram: The dynamic of the scenario situation was considered in terms of what information team members would realistically know or need to know at different times in the scenario. Ambiguous and spurious information was included and complications arising from unexpected events were added to increase the challenge. The three requirements formulated above were incorporated into the scenario in the following manner:

- Functional and status diversity: The basic information was augmented by additional domain-specific information, so slightly different versions existed for each discipline. Separate function-specific data sets were produced to supplement the written scenario.

- Geographical distribution: The scenario explicitly included onshore and offshore roles and defined the team task as developing a shared decision across both subgroups. The setup included a minimum of two locations connected by multiple communication technologies to replicate the computer-mediated interaction normal for drilling teams.

- Technological realism: Archival drilling data sets were prepared to provide in-depth and realistic background information to the written scenario. The team also had access to all software packages and tools usually available in drilling projects.

6. Definition of performance criteria: Outcome variables were defined in terms of behavioural markers to be used by facilitators, independent observers and participants to evaluate team decision making and technology use. 
The exercise consisted of two connected scenarios: the first related to issues in geo-steering through a reservoir; the second focused on the deployment and placement of swell packers during the completion. Neither of these scenarios was potentially hazardous, but were deliberately identified as being operationally and commercially biased.

\section{Implementation and Evaluation}

The pilot scenario-based training was conducted over the course of 2.5 hours with five members from one drilling team. Team members were located in two different rooms replicating onshore and offshore parts of the team. Two facilitators were involved: the second author acted as session facilitator to guide the team through the workshop and exercise and to moderate team discussions. The technology facilitator was responsible for operating the software and presenting the supporting data. Three observers took notes on participants' behaviours and points for improvement of the scenario. The team had access to a full set of communication technologies, i.e., email, phone, audio-conferencing, and a standing video-link to connect the two locations. All additional software tools and data were made available by the technology facilitator. Due to the lack of participants from offshore and one specific function, two participants were assigned to role-play these parts.

To evaluate the workshop and team processes, questionnaires were distributed to participants at three different time periods: prior to the workshop, directly after the session, and eight weeks after the training. Overall, reactions by participants to the workshop were highly positive (mean satisfaction rating $=4.3$; all scales from 1: very low to 5: very high). A comparably high rating was given on the achievement of training objectives (mean rating $=4.0$ ). The scenario itself was generally seen as challenging (mean rating $=4.0$ ), primarily because of the wealth of information presented in the scenario and the short time allocated to make the decision.

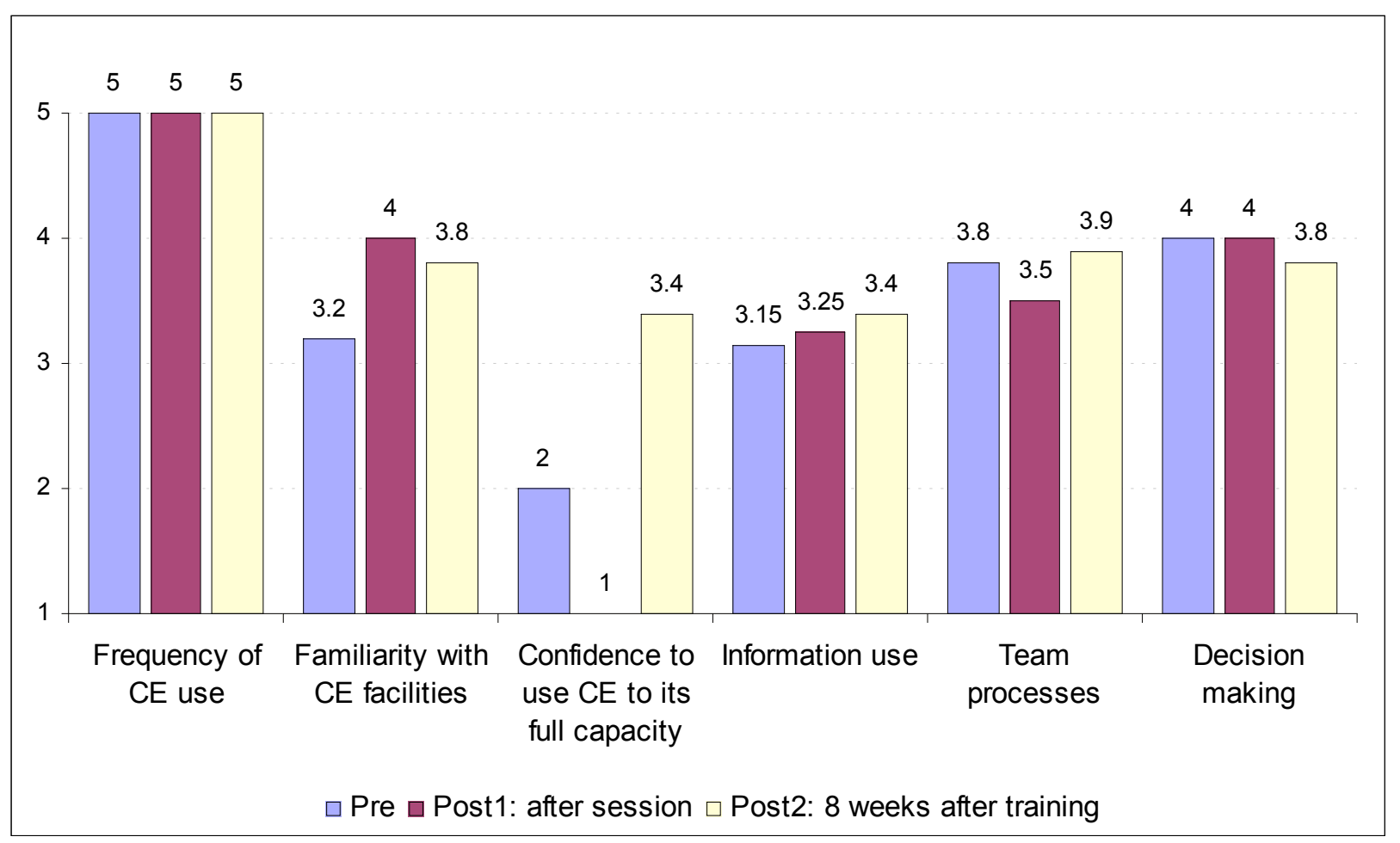

Figure 2. Pre- and Post Training Ratings by Participants

Using a facilitated group discussion at the end of the workshop immediate reactions to the exercise were gathered. Generally, participants indicated that the workshop had increased their awareness of the difficulties of distributed decision-making as well as improving their knowledge about the use of advanced technologies in critical situations. Also, several issues regarding the scenario implementation were identified. The two most important ones were:

- Distributed setup: Despite constant presence via the video-link, the offshore member was often not included in the team discussion, and decisions were taken almost exclusively by the onshore part of the team. This reflected dysfunctional team processes (replicating what is frequently reported from actual team functioning) rather than weaknesses in the scenario. This led to considerable frustrations by the role-playing 'offshore' member. Although the individual later stated that this experience had provided him with a greater understanding and appreciation of the challenges of an offshore position while decisions were being made, such experiences could easily reflect negatively on the exercise itself and therefore need to be moderated carefully by the session facilitator. 
- Technical realism and depth of information: Participants made frequent use of supporting data and tools, requesting different types of in-depth information in addition to that in the written scenario. The biggest challenge here was to strike a balance between technological realism and leaving sufficient ambiguity for decisions to remain open, as well as achieving an exact fit between supporting data and written scenario information. During the pilot we realized that the level of detail the team requested had not been fully anticipated in the preparation of data. Similarly, biggest major challenge for the technology facilitator had been to determine how much information to provide and maintaining a neutral role during the exercise, i.e. not interpreting the situation on the team's behalf.

\section{DISCUSSION}

This paper set out to discuss the adaptation of principles of scenario-based decision-making training to distributed teams using computer-mediated forms of communication. Three general design principles were identified: 1) addressing the diversity of functions in the scenario so that differences in experience and disciplinary perspective surface and can be shared; 2) maintaining geographical distribution as an aspect to be practiced in the training; and 3) technological realism to the extent that relevant skills for using computer-based tools to assess the situation and communicate and implement decisions can be practised.

Applying these principles in a pilot training session, participants' responses indicated that the exercise was seen as challenging and helped to achieve the training objectives. The biggest long-term effect, however, was found for familiarity with the technology rather than decision making (cf. Figure 2). This effect may be in part related to the difficulty of self-assessing decision-making capabilities in the absence of a real crisis, and a lack of knowledge about decision making processes. Participants who, after a comparable (although not distributed) training, did encounter an incident indicated that they felt more prepared to manage it properly (Crichton, Lauche, \& Flin, 2005). Beyond the direct benefit for the participants, this type of training also afforded benefits to the organisation, as existing technology and tools can be tested in a fail-safe environment. The SMEs involved in the process of scenario development further pointed out that the results could be used to improve processes and facilities.

\section{Implications for Training Design}

The implications for training design relate to the specific requirements of this type of computer-enhanced scenariobased training. Clearly, both the preparation and the delivery of this type of training require more time and resources in terms of SMEs' time, infrastructure, ICT, and recording equipment (audio/video recordings) than conventional tactical decision games. As demonstrated in our pilot, a distributed scenario can make effective use of participants' time, but it is not necessarily a low-cost option. It requires considerable organisational commitment and should therefore only be attempted if distributed team working has been identified as a critical training need.

While conventional TDGs are typically aimed at practising critical skills in a group of participants with the same function, this new form of TDGs adopts the diversity of roles as an essential feature. The choice of a critical situation needs to reflect this and care should be taken to ensure that all roles in a team are required for successful task completion. As this type of training is more vulnerable to the absence of functions or subgroups, considerable advanced planning and strong support by management is needed to guarantee that all essential individuals are actually present at the workshop.

One workshop generally is no guarantee of transfer of training or skills development. Ideally, scenario-based training should be conducted on a recurring basis in order to encourage good practices for behaviours and skills in the team. Such workshops could be conducted when the team has experienced a change of team members or when the team anticipates a complex or challenging situation. The workshops provide team members with the opportunity to reflect on current team functioning and to discuss and try out possible alternatives.

\section{Implications for Further Research}

The training design and findings are based so far on one pilot training session in one specific domain. More training session are planned for the same drilling community, which should allow for substantiating the potential long-term effects in a larger sample. Repeated training sessions could be used to test whether participants developed transferable skills across different critical situations. Self-report measures of decision making quality could be combined with performance indicators on a project level, such as non-productive time or recovery rate after unexpected events.

This general approach and the underlying principles should apply to other distributed setting with asymmetric subgroups such as onshore and offshore staff. In the sense that generic teamwork skills are relatively similar across different domains, it is plausible to assume that skills, knowledge and attitudes required for distributed teamwork would be comparable across domains. However, the content and actual scenario need to be developed from scratch for each domain in order to make them relevant and motivating, and ultimately to increase the likelihood of training transfer. 


\section{REFERENCES}

Alexander, D. (2000) Scenario methodology for teaching principles of emergency management, Disaster Prevention and Management, 9, 2, 89-97

Baldwin, T.T. \& Ford, J.K. (1988) Transfer of training: A review and directions for future research, Personnel Psychology, 41, 63-105.

Baltes, B., Dickson, M., Sherman, M., Bauer, C., \& LaGanke, J. (2002) Computer-mediated communication and group decision-making: A meta-analysis, Organizational Behavior and Human Decision Processes, 87, 1, $156-179$.

Badke-Schaub, P. (1999) Group effectiveness in design practice: Analysis and training by a critical-situation approach, Psychologische Beiträge, 41, 338-357.

Bayerl, P.S. \& Lauche, K. (2008) Coordinating high-interdependency tasks in asymmetric distributed teams, Proceedings of the Computer Supported Cooperative Work (CSCW) Conference, San Diego, USA.

Blackburn, R., Furst, S., \& Rosen B. (2003) Building a winning virtual team: KSAs, selection, training and evaluation, In C. Gibson \& S. Cohen (Eds.), Virtual teams that work: Creating conditions for virtual team effectiveness, San Francisco, Jossey-Bass, 95-120.

Burke, L.A. \& Hutchins, H.M. (2007) Training transfer: An integrative literature review, Human Resource Development Review, 6, 3, 263-296.

Cannon-Bowers, J. A., \& Bell, H. H. (1997). Training decision makers for complex environments: Implications of the naturalistic decision-making perspective. In C.E. Zsambok \& G.A. Klein (Eds.), Naturalistic decision-making, Lawrence Erlbaum, Mahwah, 99-110.

Cannon-Bowers, J.A., Burns, J.J., Salas, E., \& Pruitt, J.S. (1998) Advanced technology in scenario-based training. In J.A. Cannon-Bowers \& E. Salas (Eds), Making decisions under stress. Implications for individual and team training, APA, Washington, pp. 365-374.

Crede, M. \& Sniezek, J. A. (2003) Group judgment processes and outcomes in video-conferencing versus face-to-face groups, International Journal of Human-Computer Studies, 59, 875-897.

Crichton, M. (2009) Improving team effectiveness using Tactical Decision Games, Safety Science, 47, 3, $330-336$.

Crichton, M., Flin, R., \& Rattray, W. A. (2000) Training decision makers - Tactical Decision Games, Journal of Contingencies and Crisis Management, 8, 4, 208-217.

Crichton, M., Lauche, K., Flin, R. (2005) Incident command skills in the management of an oil industry drilling incident: A case study, Journal for Crisis and Contingency Management, 13, 3, 116-128.

Flin, R. (1996) Sitting in the hot seat: Leaders and teams for critical incident management, Wiley, Chichester.

Flin, R., \& Crichton, M. T. (2000) HF/GNSR 5007 Training for accident management - Stage II. Volume 4 - Tactical Decision Games Scenarios: Development guidelines. Aberdeen University, Industrial Psychology Group, Aberdeen.

Griffith, T., Sawyer, J., \& Neale, M. (2003) Virtualness and knowledge in teams: Managing the love triangle of organizations, individuals, and information technology, MIS Quarterly, 27, 2, 265-287.

Hedlund, J., Ilgen, D. R., \& Hollenbeck, J. R. (1998) Decision accuracy in computer-mediated versus face-to-face decision-making teams, Organizational Behavior and Human Decision Processes, 76, 1, 30-47.

Hertel, G., Konradt, U., \& Voss, K. (2006) Competencies for virtual teamwork: Development and validation of a webbased selection tool for members of distributed teams, European Journal of Organizational Psychology, 15, 4, 477504.

Klein Associates. (1999) Decision skills training. Instructor Guide (NOO178-97D-1043), Marine Corps Warfighting Laboratory, Fairborn, $\mathrm{OH}$.

Klein, G. (1998) Sources of power. How people make decisions, MIT Press, Cambridge.

Kozlowski, S.W.J., \& DeShon, R.P. (2004) A psychological fidelity approach to simulation-based training: Theory, research and principles. In S.G. Schiflett, L.R. Elliott, E. Salas, M.D. Coovert (Eds.). Scaled worlds: Development, validation, and applications, Aldershot, Ashgate, 75-99.

Lauche, K. (2008) Overcoming remoteness: Human factors assessment of real-time monitoring and support in drilling operations, International Journal of Technology and Human Interaction, 4, 1, 94-112.

Lauche, K. (2007) Decision making in hybrid teams: A field study in remote drilling operations, Proceedings of the Eighth International NDM Conference, Pacific Grove, CA.

Oser, R.L. (1999) A structured approach for scenario-based training, Proceedings of the 43rd Annual Meeting of the Human Factors and Ergonomics Society, Houston, TX. 
Pliske, R., McCloskey, M., \& Klein, G. (2001) Decision skills training: Facilitating learning from experience. In E. Salas \& G. Klein (Eds.), Linking expertise and naturalistic decision making, LEA: Mahwah, pp. 37-53.

Ringland, G. (1998) Scenario planning: Managing for the future, Wiley, New York.

Rosen, B., Furst, S., \& Blackburn, R. (2006) Training for virtual teams: An investigation of current practices and future needs, Human Resource Management, 45, 2, 229-247.

Salas, E., \& Cannon-Bowers, J. A. (1997) The anatomy of team training. In L. Tobias \& D. Fletcher (Eds.), Handbook on research in training, MacMillan, New York, pp. 312-335.

Schmitt, J. (1998) Designing TDGs. A tactical decision games workbook, Marine Corps University, Quantico.

Van den Bosch, K. \& Riemersma, J.B.J. (2004) Reflections on scenario-based training in tactical command. In S.G. Schiflett, L.R. Elliott, E. Salas, M.D. Coovert (Eds.). Scaled worlds: Development, validation, and applications, Aldershot, Ashgate, 1-21.

Warkentin, M. \& Beranek, P. M. (1999) Training to improve virtual team communication, Information Systems Journal, 9, 271-289.

Woltjer, R., Trnka, J., Lundberg, J., \& Johansson, B. (2006) Role-playing exercises to strengthen the resilience of command and control systems. Proceedings of the 13th European Conference on cognitive ergonomics: Trust and control in complex socio-technical systems, Zurich, Switzerland. 